\title{
Design and Analysis of Computer Experiments Based
} on a Simulation Model of Air Traffic Flow Optimization in

\section{Panama}

\author{
Juan Marcos Castillo ${ }^{1,2}$, Erick Jones ${ }^{1}$, Victoria Chen $^{3}$ and Zoila Guerra de Castillo ${ }^{2}$ \\ 1. Radio Frequency Identification Laboratory, Department of Industrial, Manufacturing and System Engineering, University of \\ Texas at Arlington, Arlington, TX, 76019, USA \\ 2. Center for Research and Innovation on Supply Chain and Logistics, Universidad Tecnológica de Panamá, Panamá, 0801, \\ Panamá \\ 3. Department of Industrial, Manufacturing and System Engineering, University of Texas at Arlington, Arlington, TX, 76019, USA
}

\begin{abstract}
There is a growing in number of operations in aviation all over the world. This growing is increasing the necessity of innovation and new technology to respond the increment of the demand. As a respond of this demand, FAA (Federal Aviation Administration) is working with NextGen in the United States and the EUROCONTROL is implementing the Point Merge as solution in the air traffic flow management in Europe. However, the FAA alternative and EUROCONTROL alternative are not mutually exclusive since Panama, a small country in Latin America, is trying to use a combination between the vectoring approach and the Point Merge in the air traffic flow management. In addition, the AAC (Autoridad de Aereonautica Civil) and the Tocumen (Tocumen International Airport) are working in a continuous collaboration between FAA and Panama with the mutual challenge to improve the actual system. As a result, the main airline of Panama, the Compañía Panameña de Aviación (COPA Airlines), and the Autoridad de Aeronáutica Civil (AAC) constructed a simulation model to select an air traffic flow alternative that can be able to change the actual situation. In other words, COPA Airlines and AAC are pursuing the minimization of the numbers of conflicts, the number of sequence actions, the flight time, the track flight distance and the fuel burn. Furthermore, this study aims to use the final draft of this previous analysis based on a simulation methodology to conduct a Design and Analysis of Computer Experiments with the final objective to increment the statistical significance of the actual model.
\end{abstract}

Key words: Air traffic management, air traffic KPIs, air traffic rules, ground traffic rules, season itinerary, DACE (Design and Analysis of Computer Experiments), statistically significance.

\section{Introduction}

The air transportation is growing fast in the whole world, which means that the evolution of the industry

Corresponding author: Juan Castillo, Ph.D. in industrial engineering, Scientist at RAID LABS (www.uta.edu/rfid), logistics, transportation, data science and process improvement; Erick C. Jones, Ph.D., P.E., CLSSMBB, MSIE, George and Elizabeth Endowed Professor, Associate Dean of Graduate Affairs, College of Engineering, Director RAID LABS (www.uta.edu/rfid), University of Texas at Arlington;

Victoria Chen, Ph.D. director, Faculty \& Student Research Development, Professor, Industrial, Manufacturing, \& Systems Engineering, University of Texas at Arlington;

Zoila Yadira Guerra de Castillo, Ph.D. Professor-Research Leader, CIILCA, Facultad de Ingeniería Industrial, Universidad Tecnológica de Panamá. is demanding changes in the air traffic flow and airports efficiency. For example, the Airbus' Global Market Forecast for 2016-2035 anticipates that air traffic will grow at 4.5 percent annually, in other words, 33,000 new passengers [1].

In addition, the last 40 years the volume of air logistic growth was $7 \%$. The average in the last five years was $3.8 \%$ against an average of $3 \%$ in the rest of the world. The forecast of growth in air logistic for the next 20 years is $5-6 \%$. The quote of air logistic is $2 \%$ of the world commerce in weight $(\mathrm{t})$ and $35 \%$ in USD [2].

As Fig. 1 shows, the world air cargo traffic is 
increasing $2.6 \%$ per year, and the expected growth in passenger air transportation is " $4.9 \%$ over the period of 2010-2030" [3]/

Consequently, this constant increment in air traffic has not found an adequate expansion of airport facilities and flight assistance [4]. These situations presented in an airport, in everyday life, are very unpredictable because those depends on several factors, such as holidays, peak hours, weather conditions, the number of flights and the increment of passengers [5]. Those factors have a strong impact in the performance of the airports operations. Since, the limitations in capacity at specific ranges of time during the day, are several issues in the operation, such as large queues in the airspace, congestion in the taxi flow in the ground, waiting lines to depart. Furthermore, these air queues are producing more delays, cost impact, and increment in the pollution.

Furthermore, this growing in the air traffic industry is increasing the necessity of new technology and new knowledge to respond the actual demand. Consequently, FAA is working with NextGen in the United States [6] and the EUROCONTROL is implementing the Point Merge as solution in the air traffic flow management in Europe (EUROCONTROL 16, Ivanescu, et al. 9, Invanescu, et. al. 10, Ozlem, M. 14) [7-10]. However, the FAA alternative and EUROCONTROL alternative are not mutually exclusive since Panama, a small country in Latin America, is trying to use a combination between the vectoring approach and the Point Merge in their air traffic flow management. In addition, the AAC (Autoridad de Aereonautica Civil) and the Tocumen (Tocumen International Airport) are working in a continuous collaboration between FAA and Panama in order to improve the actual system. As a result, the main airline of Panama, COPA Airlines, and AAC are working on a simulation model. The objective of this simulation modeling is to select an air traffic alternative that can be able to improve the actual situation. In other words, COPA and AAC are looking to minimize the numbers of conflicts, the number of sequence actions, the flight time, the track flight distance and the fuel burn.

In order to understand the context of Panama, there are some facts to take into consideration. The main industry of Panama is the transportation, since the Panama Canal. Therefore, the growing of logistics and transportation service is $24.3 \%$ of the GDP of the Country. (ALG Panama 1) [2]. This growth is challenging the air traffic system since the increment of flights. The changes in the Demand are making several

\section{World air cargo traffic will more than double over the next 20 years}

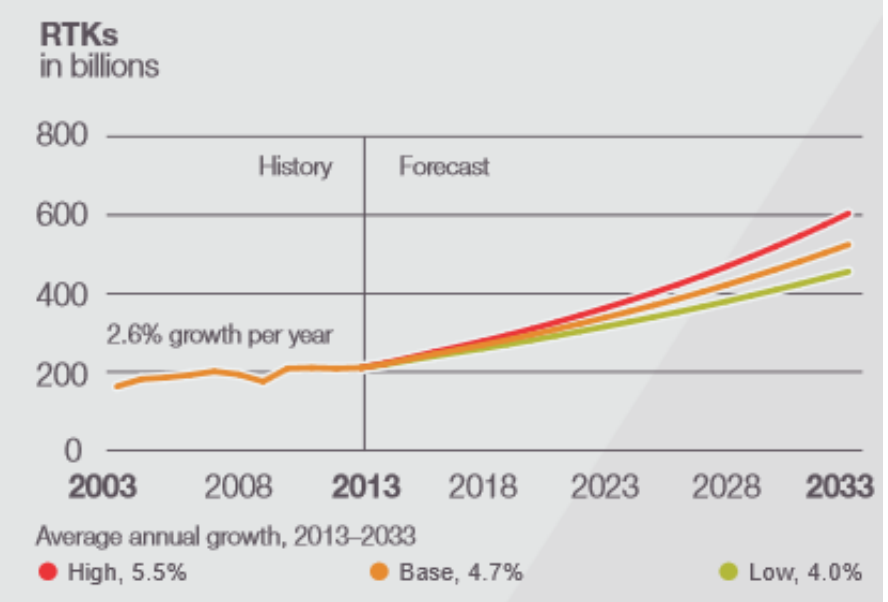

Fig. 1 Forecast air cargo growing [11]. 
issues in the actual air traffic management operation.

Fig. 2 shows the growth of the Tocumen International Airport, the main airport of Panama. The passenger movement through Tocumen grew steadily during the last years, with a growing rate of $11.8 \%$ during the 2013 comparing with previous years. This study is based on the arrivals and departures operations of the Tocumen International Airport.

As it is mentioned before, COPA and AAC were working on a plan to improve the air operation efficiency using a discrete event simulation model. The software used is named as TAAM (total airspace and airport modeller) 12]. These simulation models are based on some rules in terms of airport description and geographical location of the airport, the layout of the airport, the itinerary of the flights and the airways. The simulations are all constructed on the actual situation of the airport, which is in expansion. So, the layout of the airport gates, taxi ways and runways are going to change in the near future.

The main experiments conducted by COPA and AAC are five models of air traffic flow [13] are the actual situation, an alternative based on Vectoring, Point Merge version 1, Point Merge version 2, and
Final Draft.

The Final Draft was made it by COPA as a mix of the testing models. However, this experiment was not constructed with an experimental design and it does not include the weather seasoning.

Based on COPA analysis, there exist several factors that they did not take into consideration, but important to be tested in the near future. Those factors are the wind, the weather events, the aircraft weight, domestic flights, over flights, aircraft speed and Altitude. In addition, the demand seasons, the air traffic rules and the ground traffic rules, are the focus of this research.

The most important KPIs (Key Performance Indicators) from COPA stand point are the fuel burn, the track mile distance and the flight time. On the other hand, the most important KPIs for the AAC are the number of sequencing actions and the airborne conflicts. Therefore, the goal of both organizations is to optimize the five KPIs.

In contrast, the majority of these studies using simulation models for air traffic flow management do not use any methodology to understand the impact of the factors at certain levels. However, there exist some studies about airport operation that use Monte Carlo

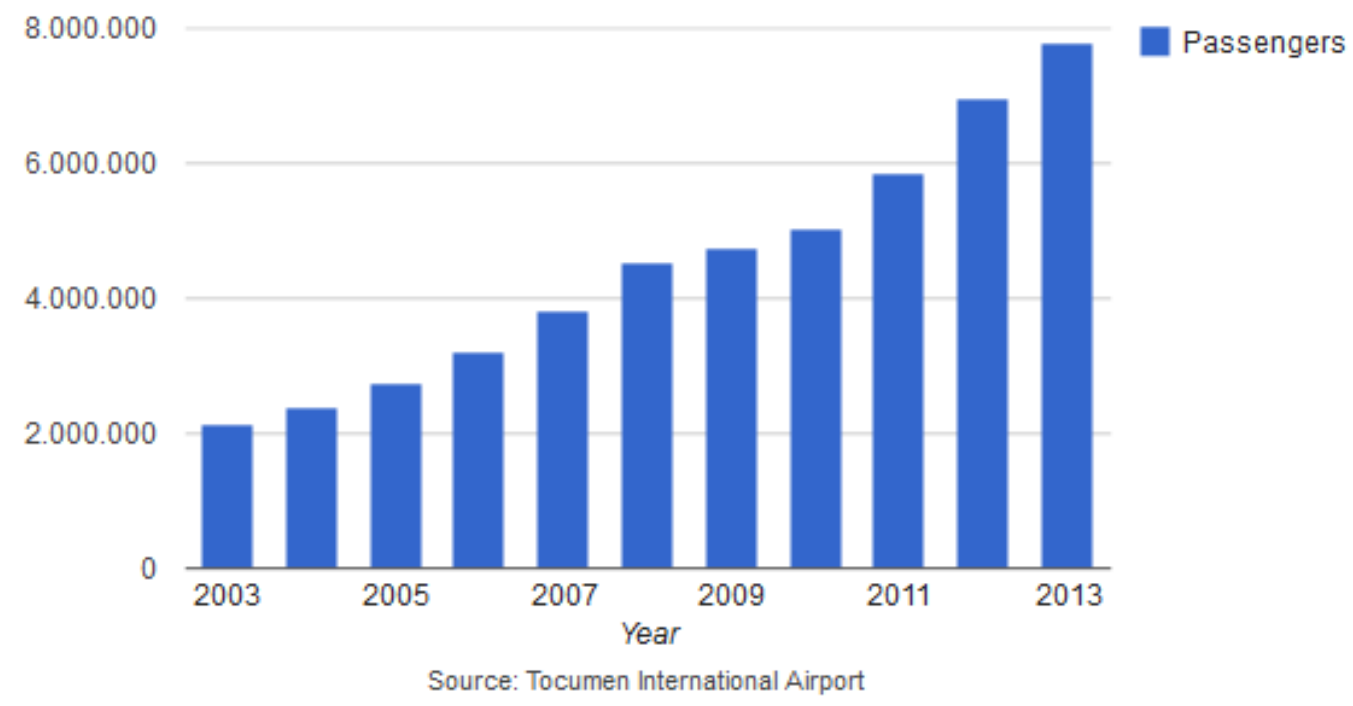

Fig. 2 Historical growing of passengers using the Tocumen International Airport [14]. 
simulation to understand the presence of uncertainties [15]. In addition, studies are using queuing theory with simulation models [16]. Consequently, the absent of statistical analysis based on computer experimentation is the motivation of this study.

Thus, this study aims to include design and analysis of computer experiments to understand how the factors at certain levels can impact the Key performance indicators or response variables. So, the objective of this study is to analyze how the itinerary by season (low season of demand or high season of demand), the ground traffic rules and the air traffic rules can affect the air traffic management KPIs. As a secondary objective of the research, it is to present a procedure to follow for future simulation analysis.

\section{Design and Model Definition}

\subsection{Factors}

\subsubsection{Itinerary}

The itinerary is a data base which includes Type of aircraft, license plate, origin, destiny, departure time and arrival time. Each row of the data base is a flight.

\subsubsection{Ground Traffic Rules}

The ground traffic rules is a time distance between aircraft during the arrival, which is between $1 \mathrm{~min}$ to 2 $\min$.

\subsubsection{Air Traffic Rules}

The air traffic rule is the distance in nautical miles between aircraft during the approximation to the airport which range lies between $3 \mathrm{NM}$ as a minimum and $10 \mathrm{NM}$.

Consequently, the data set of itinerary is a factor with two levels (high season data set, low season data set), the ground traffic rules is a factor with three levels ( $1 \mathrm{~min}, 1.5 \mathrm{~min}$ and $2 \mathrm{~min}$ ) and the air traffic rules is a factor with four levels ( $3 \mathrm{NM}, 5 \mathrm{NM}, 7 \mathrm{NM}$, and $10 \mathrm{NM})$.

\subsection{Response Variables}

When COPA airlines use to run the simulation, they obtain five outputs as response variables per each model. The key performance indicators for the air traffic management in Panama are the sequencing actions (number of interactions per day), the airborne conflicts (number of conflicts per day), the flight time (hours per day), the track mile distance (nautical miles per day) and the fuel burn (gallon per day).

\subsection{Experimental Design and Linear Model}

The first experiment conducted by COPA was used a fixed ground traffic rule, a fixed air traffic rule, and a data set from the high season.

Therefore, our experimental design is a three factor complete factorial experiment. Table 1 shows the coded layout of the experiment. The following are the factors described with their levels:

Factor 1: Itinerary (1-high season, 2-low season);

Factor 2: Ground traffic rules $(1-1 \mathrm{~min}, 2-1.5$ $\min , 3-2 \mathrm{~min}$ );

Factor 3: Air traffic rules $(1-3 \mathrm{NM}, 2-5 \mathrm{NM}$, 3-7 NM, 4-10 NM).

Table 1 shows the coded layout that was used to conduct the 24 experiments. Those experiments were conducted directly in the COPA office, since the limited license in place that they have. In addition, there is just one replication made it per each experiment.

In order to achieve flexibility and efficiency, it is better to select the full factorial design to run the experiments. This kind of design was originally used in design of experiments for physical experiments, but it is suitable to apply in computer experiments as well [17].

The linear model formulation per each response variable is as follows:

$$
\begin{aligned}
& \quad Y_{i j k t}=\mu \ldots+\alpha_{i}+\beta_{j}+\gamma_{k}+ \\
& (\alpha \beta)_{i j}+(\alpha \gamma)_{i k}+(\beta \gamma)_{j k} \\
& +(\alpha \beta \gamma)_{i j k}+\varepsilon_{i j k t} \\
& \text { for } i=1, \ldots, \mathrm{a}, j=1, \ldots, \mathrm{b}, k=1, \ldots, \mathrm{c}, \text { and } t=1, \ldots, \mathrm{r} .
\end{aligned}
$$


Table 1 Layout coded of the three factor complete factorial design.

\begin{tabular}{lll}
\hline Factor 1 & Factor 2 & Factor 3 \\
\hline 1 & 1 & 1 \\
1 & 1 & 2 \\
1 & 1 & 3 \\
1 & 1 & 4 \\
1 & 2 & 1 \\
1 & 2 & 2 \\
1 & 2 & 3 \\
1 & 2 & 4 \\
1 & 3 & 1 \\
1 & 3 & 2 \\
1 & 3 & 3 \\
1 & 3 & 4 \\
\hline
\end{tabular}

\begin{tabular}{lll} 
Factor 1 & Factor 2 & Factor 3 \\
\hline 2 & 1 & 1 \\
2 & 1 & 2 \\
2 & 1 & 3 \\
2 & 1 & 4 \\
2 & 2 & 1 \\
2 & 2 & 2 \\
2 & 2 & 3 \\
2 & 2 & 4 \\
2 & 3 & 1 \\
2 & 3 & 2 \\
2 & 3 & 3 \\
2 & 3 & 4 \\
\hline
\end{tabular}

$\varepsilon_{i j k t}$ are iid $\mathrm{N}\left(0, \sigma^{2}\right)$;

$Y_{i j k t}=t$-th response observed for $\operatorname{trt}(i, j, k)$;

$\mu \ldots=$ is the overall mean;

$\alpha_{i}=$ is the effect on the response due to the $i$ th level of factor 1 ;

$\beta_{j}=$ is the effect on the response due to the $j$ th level of factor 2 ;

$\gamma_{k}=$ is the effect on the response due to the $k$ th level of factor 3 ;

$(\alpha \beta)_{i j}=$ is the interaction effect in $i$ th and $j$ th of factors 1 and 2;

$(\alpha \gamma)_{i k}=$ is the interaction effect in the $i$ th and $k$ th of factors 1 and 3 ;

$(\beta \gamma)_{j k}=$ is the interaction effect in the $j$ th and $k$ th of factors 2 and 3 ;

$(\alpha \beta \gamma)_{i j k}=$ is the interaction effect in $i$ th, $j$ th and $k$ th of factors 1,2 and 3 .

COPA mentioned that there is a way to obtain the probabilistic data, but the analyst asked us to run the model without stochastic data, since they made the previous experiments using deterministic output. Consequently, the mathematical model is going to suffer a modification, since there is not going to consider any interaction effect with the three factors in conjunction.

The linear model formulation per each response variable is going to be as follow:

$$
\begin{gathered}
Y_{i j k t}=\mu_{\ldots}+\alpha_{i}+\beta_{j}+\gamma_{k}+(\alpha \beta)_{i j}+ \\
(\alpha \gamma)_{i k}+(\beta \gamma)_{j k}+\varepsilon_{i j k t}
\end{gathered}
$$

for $i=1, \ldots, \mathrm{a}, j=1, \ldots, \mathrm{b}, k=1, \ldots, \mathrm{c}$, and $t=1, \ldots, \mathrm{r}$. $\varepsilon_{i j k t}$ are iid $\mathrm{N}\left(0, \sigma^{2}\right)$;

$Y_{i j k t}=t$-th response observed for $\operatorname{trt}(i, j, k)$;

$\mu \ldots=$ is the overall mean;

$\alpha_{i}=$ is the effect on the response due to the $i$ th level of factor 1 ;

$\beta_{j}=$ is the effect on the response due to the $j$ th level of factor 2 ;

$\gamma_{k}=$ is the effect on the response due to the $k$ th level of factor 3 ;

$(\alpha \beta)_{i j}=$ is the interaction effect in $i$ th and $j$ th of factors 1 and 2;

$(\alpha \gamma)_{i k}=$ is the interaction effect in the $i$ th and $k$ th of factors 1 and 3 ;

$(\beta \gamma)_{j k}=$ is the interaction effect in the $j$ th and $k$ th of factors 2 and 3.

\section{The Simulation Experiments}

\subsection{The Simulation Model}

\subsubsection{The Simulation Software}

The TAAM is a fast-time gate-to-gate simulator of airport and airspace operations. This software can simulate 4D and 3D. TAAM enables the analyst to 
identify the system benefits of such changes in the airport layout for gates, taxi ways and runways. In addition, other air space requirements [18].

Some of the features are the 3D multi-color models of airports and aircrafts, 4D full airspace \& flight profile calculations, detailed ground functionality, detailed airside functionality, a flexible rule base to accommodate different modelling requirements, statistical data generated in a wide variety of report forms, direct output to spreadsheet and database tools for further in-depth analysis [18].

\subsubsection{The Simulation Model}

The simulation model consists in set the static files (in our case the itineraries), the parameter setting, and the rules (air traffic rules and ground traffic rules for this experiment).

There exist other parameters that most keep standard, such as Airport layout (32 gates), two runways, three taxi ways, and the airport geolocation [19]. The Airport with the specifications most be drawing in AutoCAD and uploaded in the software. In addition, there is an airspace design, so the regions of the airspace and the air ways must be drawing.

\subsection{The Itinerary Samples}

In order to obtain the sample, the department of Operation Efficiency of COPA analyzed the air traffic flow from 1 st of January to July 7 th and took to days one from the high season and another from the low season. Then, COPA took, using another software called AIMS, the itinerary for each day. However, the procedure says that it is required to take at minimum of three days. This is necessary since they need to take from the 05:00 a.m. of the actual day to the 05:00 a.m. of the day after the actual day. This is necessary to keep the continuity of the simulation in terms of time. As an explanation, COPA takes the 05:00 as a reference, since is the hour zone of Panama based on the Greenwich Meridian.

As we mention before, the itineraries contain the type of aircraft, the license plate, the origin, the destiny, the departure time and the arrival time. This information is per flight.

\subsection{Simulation Output}

In order to obtain the output, it is necessary to use the sample itinerary which is part of the input information. Then, it is important to change some of the air traffic rules and the ground traffic rules in two windows and in the map of the air space. The areas of the map changed are for approximation to the Tocumen Airport. In other words, these rules affect in some ways the departure, depending if the runways have not conflict in the departure, and these rules affect all the arrival queues in the air space of Panama.

Therefore, the simulation is going to run per five days, just to check any outlier and maintain the continuity. However, the model has a rule to stop in some point (which is 05:00 a.m. as we mention before) to record the information for the main in study. There is another rule to stop at 05:00 a.m. the next day to stop the recording, this process recording is manually. After the model stop, it is necessary to run the three different queries, two of them was customized by COPA for the previous analysis.

In addition, the output of time is in seconds and the fuel consumption is Kilograms, so it is necessary to convert those. The flight time is converted in hours of flight and the fuel burn changes in gallons.

\section{Statistical Analysis}

For the statistical analysis, it is presented each response variable separately to analyze the effect of each factor which their levels. The objective is to know how the factors and the levels affect each response variable separately. For this analysis the software used is SAS. Therefore, the analysis shows the ANOVA table with the main factors and the interaction effects. However, it is not included the full interaction with the three factors since there is not replications. The model does not include the full interaction effect between the three factors, since the 
simulation model is deterministic. Furthermore, the interaction plot and the "Tukey" comparison per each model is presented with the followed discussion.

\subsection{Analysis of Variance}

The analysis of variance conducted presents the results per each response variable. Therefore, we are working with five different models and five different analyses. Significance level used for the ANOVA is 0.1 as an alpha value.

Consequently, the hypothesis for the linear model stands as:

$\mathrm{H}_{\mathrm{o}}$ : no difference in the treatments/full model is not statistically significant.

$\mathrm{H}_{1}$ : at least two treatments are different/full model is statistically significant.

So, the $p$-value must be less than the alpha value 0.1 to reject $H_{0}$. Then the model is statistically significant.

The hypothesis analyzed based on the ANOVA tables for interaction effects are:

$\mathrm{H}_{0}{ }^{12}$ : factor 1 and factor 2 interaction is negligible.

$\mathrm{H}_{1}{ }^{12}$ : factor 1 and factor 2 interaction is not negligible.

$\mathrm{H}_{0}{ }^{13}$ : factor 1 and factor 3 interaction is negligible.

$\mathrm{H}_{1}{ }^{13}$ : factor 1 and factor 3 interaction is not negligible.

$\mathrm{H}_{0}{ }^{23}$ : factor 2 and factor 3 interaction is negligible.

$\mathrm{H}_{1}^{23}$ : factor 2 and factor 3 interaction is not negligible.

The decision rule for those hypotheses is that the $p$-value must be less than the alpha value 0.1 to reject $\mathrm{H}_{\mathrm{o}}$.

The evaluation of the five models using the ANOVA approach concludes that at 0.1 level of significance all the linear models are statistically significant. So, we reject $\mathrm{H}_{0}$ in our first hypothesis analysis. However, the interactions between factor 2 and the other factors are greater than 0.1 as an alpha value, which means we fail to reject $H_{o}$ in the interaction hypothesis. In contrast, the interaction between factor 1 and factor 3 is significant and we can reject $\mathrm{H}_{0}$.

The hypothesis analyzed based on the ANOVA table for the main effects is:

$\mathrm{H}_{0}^{2}$ : main effect for factor 2 is negligible.

$\mathrm{H}_{1}^{2}$ : main effect for factor 2 is not negligible.

The decision rule for this hypothesis is that the $p$-value must be less than the alpha value of 0.1 to reject $\mathrm{H}_{\mathrm{o}}$.

The GTRules (ground traffic rules) or factor 2 is not significant at 0.1 level, since the three-way ANOVA shows the $p$-value of GTRules (factor 2). So, we fail to reject $\mathrm{H}_{\mathrm{o}}$ and the main effect of factor 2 is negligible. There is not necessity to test the other main effects since, the interaction between factor 1 and 3 is not negligible.

Fig. 3 shows that the $p$-value of GTRules is 0.738 when the number of sequence actions as a response variable. Fig. 4 shows that the $p$-value of GTRules is 0.2776 when the response variable is the number of conflicts. Fig. 5 shows that the $p$-value of GTRules is 0.7511 when the response variable is the flight time. Fig. 6 presents that the $p$-value of GTRules is 0.7026 when the track mile distance is the response variable. Fig. 7 presents that the $p$-value of GTRules is 0.7382 when the fuel burn is the response variable. In other words, the GTRules has not significant effect in the dependent variables or air traffic KPIs.

As it is mentioned before, the "Iti" or itinerary and the ATRules or air traffic rules are statistically significant at 0.1 level. So, ATRules and itinerary have an effect over the air traffic KPIs. Therefore, the following analysis of interaction plots and Tukey pairwise comparison is going to be considering only between those two factors.

\subsection{Interaction Plots}

The objective of the interaction plots is to understand how the interaction can affect each response variable. 

Air Traffic Flow Optimization in Panama

\begin{tabular}{|c|c|c|c|c|c|c|c|}
\hline Source & DF & \multicolumn{2}{|c|}{ Sum of Squares } & \multicolumn{2}{|c|}{ Mean Square } & F Value & $\mathrm{Pr}>\mathrm{F}$ \\
\hline Model & \multicolumn{2}{|c|}{17} & 22519.16667 & \multicolumn{2}{|c|}{1324.65686} & 195.44 & $<.0001$ \\
\hline Error & \multicolumn{2}{|c|}{6} & 40.66667 & \multicolumn{2}{|c|}{6.77778} & & \\
\hline Corrected Total & \multicolumn{2}{|c|}{23} & 22559.83333 & & & & \\
\hline & \multicolumn{2}{|c|}{ R-Square } & Coeff Var Rc & Root MSE & \multicolumn{2}{|c|}{ Sact Mean } & \\
\hline & \multicolumn{2}{|c|}{0.998197} & 1.577032 & 2.603417 & \multicolumn{2}{|c|}{165.0833} & \\
\hline \multicolumn{2}{|l|}{ Source } & DF & Type I SS & \multicolumn{2}{|c|}{ Mean Square } & F Value & $\operatorname{Pr}>\mathrm{F}$ \\
\hline \multicolumn{2}{|l|}{ Iti } & 1 & 7561.50000 & \multicolumn{2}{|c|}{7561.50000} & 1115.63 & $<.0001$ \\
\hline \multicolumn{2}{|l|}{ GTRules } & 2 & 4.33333 & \multicolumn{2}{|c|}{2.16667} & 0.32 & 0.7380 \\
\hline \multicolumn{2}{|l|}{ ATRules } & 3 & 14345.83333 & \multicolumn{2}{|c|}{4781.94444} & 705.53 & $<.0001$ \\
\hline \multicolumn{2}{|l|}{ Iti*GTRules } & 2 & 37.00000 & \multicolumn{2}{|c|}{18.50000} & 2.73 & 0.1436 \\
\hline ItiATRules & & 3 & 517.83333 & 172 & 61111 & 25.47 & 0.0008 \\
\hline GTRules*ATR & & 6 & 52.66667 & & 77778 & 1.30 & 0.3808 \\
\hline Source & & DF & Type III SS & Mean S & quare & F Value & $\operatorname{Pr}>F$ \\
\hline Iti & & 1 & 7561.50000 & 7561 & .50000 & 1115.63 & $<.0001$ \\
\hline GTRules & & 2 & 4.33333 & & 16667 & 0.32 & 0.7380 \\
\hline ATRules & & 3 & 14345.83333 & 4781 & 94444 & 705.53 & $<.0001$ \\
\hline ItiGTRules & & 2 & 37.00000 & & .50000 & 2.73 & 0.1436 \\
\hline Iti*ATRules & & 3 & 517.83333 & 172 & 61111 & 25.47 & 0.0008 \\
\hline GTRules ${ }^{\star}$ ATR & & 6 & 52.66667 & & 77778 & 1.30 & 0.3808 \\
\hline
\end{tabular}

Fig. 3 ANOVA table for sequence actions as a dependent variable.

\begin{tabular}{|l|r|r|r|r|r|}
\hline Source & DF & Sum of Squares & Mean Square & F Value & Pr $>$ F \\
\hline Model & 17 & 3835.833333 & 225.637255 & 26.72 & 0.0003 \\
\hline Error & 6 & 50.666667 & 8.444444 & & \\
\hline Corrected Total & 23 & 3886.500000 & & & \\
\hline
\end{tabular}

\begin{tabular}{|c|c|c|c|c|c|c|}
\hline \multirow{3}{*}{ Source } & are & \multirow{2}{*}{\begin{tabular}{|r|r} 
Coeff Var & $R$ \\
7.597209 & \\
\end{tabular}} & \multirow{2}{*}{$\begin{array}{r}\text { Root MSE } \\
2.905933\end{array}$} & \multirow{2}{*}{\multicolumn{2}{|c|}{\begin{tabular}{r|} 
Cflict Mean \\
38.25000
\end{tabular}}} & \multirow[b]{3}{*}{$\mathrm{Pr}>\mathrm{F}$} \\
\hline & & & & & & \\
\hline & DF & Type I SS & \multicolumn{2}{|c|}{ Mean Square } & F Value & \\
\hline Iti & 1 & 864.000000 & \multicolumn{2}{|c|}{864.000000} & 102.32 & $<.0001$ \\
\hline GTRules & 2 & 27.000000 & \multicolumn{2}{|c|}{13.500000} & 1.60 & 0.2776 \\
\hline ATRules & 3 & 2723.500000 & \multicolumn{2}{|c|}{907.833333} & 107.51 & $<.0001$ \\
\hline Iti*GTRules & 2 & 3.000000 & \multicolumn{2}{|c|}{1.500000} & 0.18 & 0.8415 \\
\hline Iti^ATRules & 3 & 192.333333 & \multicolumn{2}{|c|}{64.111111} & 7.59 & 0.0182 \\
\hline GTRules*ATRules & 6 & 26.000000 & \multicolumn{2}{|c|}{4.333333} & 0.51 & 0.7815 \\
\hline Source & DF & Type III SS & \multicolumn{2}{|c|}{ Mean Square } & F Value & $\operatorname{Pr}>F$ \\
\hline Iti & 1 & 864.000000 & \multicolumn{2}{|c|}{864.000000} & 102.32 & $<.0001$ \\
\hline GTRules & 2 & 27.000000 & \multicolumn{2}{|c|}{13.500000} & 1.60 & 0.2776 \\
\hline ATRules & 3 & 2723.500000 & \multicolumn{2}{|c|}{907.833333} & 107.51 & $<.0001$ \\
\hline Iti*GTRules & 2 & 3.000000 & \multicolumn{2}{|c|}{1.500000} & 0.18 & 0.8415 \\
\hline ItiATRules & 3 & 192.333333 & \multicolumn{2}{|c|}{64.111111} & 7.59 & 0.0182 \\
\hline GTRules*ATRules & 6 & 26.000000 & & 333333 & 0.51 & 0.7815 \\
\hline
\end{tabular}

Fig. 4 ANOVA table for number of conflicts as a dependent variable. 

Air Traffic Flow Optimization in Panama

\begin{tabular}{|c|c|c|c|c|c|c|c|}
\hline Source & DF $\mathrm{S}$ & \multicolumn{2}{|c|}{ Sum of Squares } & \multicolumn{2}{|c|}{ Mean Square } & F Value & $\mathrm{Pr}>\mathrm{F}$ \\
\hline Model & 17 & \multicolumn{2}{|c|}{216612.1440} & \multicolumn{2}{|c|}{12741.8908} & 3714.94 & $<.0001$ \\
\hline Error & 6 & \multicolumn{2}{|c|}{20.5794} & \multicolumn{2}{|r|}{3.4299} & & \\
\hline Corrected Total & 23 & \multicolumn{2}{|c|}{216632.7234} & & & & \\
\hline & R-Square & Coeff Var & \multicolumn{2}{|c|}{ Root MSE } & \multicolumn{2}{|c|}{ FTime Mean } & \\
\hline & 0.999905 & 0.151742 & \multicolumn{2}{|c|}{1.851999} & \multicolumn{2}{|c|}{1220.496} & \\
\hline Source & DF & \multicolumn{2}{|c|}{ Type I SS } & \multicolumn{2}{|c|}{ Mean Square } & F Value & $\operatorname{Pr}>F$ \\
\hline Iti & 1 & \multicolumn{2}{|c|}{181381.1840} & \multicolumn{2}{|c|}{181381.1840} & 52882.3 & $<.0001$ \\
\hline GTRules & 2 & \multicolumn{2}{|c|}{2.0598} & \multicolumn{2}{|r|}{1.0299} & 0.30 & 0.7511 \\
\hline ATRules & 3 & \multicolumn{2}{|c|}{32100.5313} & \multicolumn{2}{|c|}{10700.1771} & 3119.67 & $<.0001$ \\
\hline Iti*GTRules & 2 & \multicolumn{2}{|c|}{1.9931} & & 0.9965 & 0.29 & 0.7578 \\
\hline ItiATRules & 3 & 3102.31 & 106 & & 34.1035 & 301.50 & $<.0001$ \\
\hline GTRules*ATRules & 6 & 24.06 & 652 & & 4.0109 & 1.17 & 0.4271 \\
\hline Source & DF & Type III & SS & Mean & Square & F Value & $\operatorname{Pr}>\mathrm{F}$ \\
\hline Iti & 1 & 181381.18 & 840 & 18138 & 81.1840 & 52882.3 & $<.0001$ \\
\hline GTRules & 2 & 2.05 & 598 & & 1.0299 & 0.30 & 0.7511 \\
\hline ATRules & 3 & 32100.53 & 313 & 1070 & 00.1771 & 3119.67 & $<.0001$ \\
\hline Iti”GTRules & 2 & 1.99 & 931 & & 0.9965 & 0.29 & 0.7578 \\
\hline Iti*ATRules & 3 & 3102.31 & 106 & & 34.1035 & 301.50 & $<.0001$ \\
\hline GTRules*ATRules & 6 & 24.06 & 652 & & 4.0109 & 1.17 & 0.4271 \\
\hline
\end{tabular}

Fig. 5 ANOVA table for flight time as a dependent variable.

\begin{tabular}{|l|r|r|r|r|r|r|}
\hline Source & DF & Sum of Squares & Mean Square & F Value & Pr $>$ F \\
\hline Model & 17 & 34949883849 & 2055875521 & 3248.03 & $<.0001$ \\
\hline Error & 6 & 3797769 & 632961 & & \\
\hline Corrected Total & 23 & 34953681618 & & & \\
\hline & R-Square & Coeff Var & Root MSE & TMDist Mean & \\
\hline & 0.999891 & 0.159594 & 795.5888 & 498508.5 & \\
\hline Source & DF & Type I SS & Mean Square & F Value & Pr $>$ F \\
\hline Iti & 1 & 29912584945 & 29912584945 & 47258.1 & $<.0001$ \\
\hline GTRules & 2 & 474151 & 237076 & 0.37 & 0.7026 \\
\hline ATRules & 3 & 4560621424 & 1520207141 & 2401.74 & $<.0001$ \\
\hline Iti*GTRules & 2 & 287703 & 143852 & 0.23 & 0.8033 \\
\hline Iti*ATRules & 3 & 471737542 & 157245847 & 248.43 & $<.0001$ \\
\hline GTRules*ATRules & 6 & 4178084 & 696347 & 1.10 & 0.4554 \\
\hline Source & DF & Type III SS & Mean Square & F Value & Pr $>$ F \\
\hline Iti & 1 & 29912584945 & 29912584945 & 47258.1 & $<.0001$ \\
\hline GTRules & 2 & 474151 & 237076 & 0.37 & 0.7026 \\
\hline ATRules & 3 & 4560621424 & 1520207141 & 2401.74 & $<.0001$ \\
\hline Iti*GTRules & 2 & 287703 & 143852 & 0.23 & 0.8033 \\
\hline Iti*ATRules & 3 & 471737542 & 157245847 & 248.43 & $<.0001$ \\
\hline GTRules*ATRules & 6 & 4178084 & 696347 & 1.10 & 0.4554 \\
\hline
\end{tabular}

Fig. 6 ANOVA table for track mile distance as a dependent variable. 
Air Traffic Flow Optimization in Panama

\begin{tabular}{|c|c|c|c|c|c|c|c|}
\hline Source & DF $S$ & \multicolumn{2}{|c|}{ Sum of Squares } & \multicolumn{2}{|c|}{ Mean Square } & F Value & $\mathrm{Pr}>\mathrm{F}$ \\
\hline Model & 17 & \multicolumn{2}{|c|}{ 1.6263486E13 } & \multicolumn{2}{|c|}{956675650912} & 2099.05 & $<.0001$ \\
\hline Error & 6 & \multicolumn{2}{|c|}{2734594642} & \multicolumn{2}{|c|}{455765773.67} & & \\
\hline Corrected Total & 23 & \multicolumn{2}{|c|}{$1.6266221 \mathrm{E} 13$} & & & & \\
\hline & R-Square & Coeff Var & \multicolumn{2}{|c|}{ Root MSE } & \multicolumn{2}{|c|}{ FuelB Mean } & \\
\hline & 0.999832 & 0.177819 & \multicolumn{2}{|c|}{21348.67} & \multicolumn{2}{|c|}{12005824} & \\
\hline Source & DF & \multicolumn{2}{|c|}{ Type I SS } & \multicolumn{2}{|c|}{ Mean Square } & F Value & $\operatorname{Pr}>\mathrm{F}$ \\
\hline Iti & 1 & \multicolumn{2}{|c|}{ 1.3020771E13 } & \multicolumn{2}{|c|}{ 1.3020771E13 } & 28569.0 & $<.0001$ \\
\hline GTRules & 2 & \multicolumn{2}{|c|}{206192953.04} & \multicolumn{2}{|c|}{103096476.52} & 0.23 & 0.8041 \\
\hline ATRules & 3 & \multicolumn{2}{|c|}{ 2.9608878E12 } & \multicolumn{2}{|c|}{986962604521} & 2165.50 & $<.0001$ \\
\hline ItiGTRules & 2 & \multicolumn{2}{|c|}{291163925.63} & \multicolumn{2}{|c|}{145581962.82} & 0.32 & 0.7382 \\
\hline ItiATRules & 3 & \multicolumn{2}{|c|}{278828016005} & \multicolumn{2}{|c|}{92942672002} & 203.93 & $<.0001$ \\
\hline GTRules*ATRules & 6 & 2502124 & 108 & 41702 & 0684.67 & 0.91 & 0.5416 \\
\hline Source & DF & Type III & SS & Mean & Square & F Value & $\operatorname{Pr}>\mathrm{F}$ \\
\hline Iti & 1 & 1.3020771 & E13 & 1.3020 & $771 \mathrm{E} 13$ & 28569.0 & $<.0001$ \\
\hline GTRules & 2 & 20619295 & 3.04 & 10309 & 6476.52 & 0.23 & 0.8041 \\
\hline ATRules & 3 & 2.9608878 & E12 & 986962 & 2604521 & 2165.50 & $<.0001$ \\
\hline Iti*GTRules & 2 & 29116392 & 5.63 & 14558 & 1962.82 & 0.32 & 0.7382 \\
\hline ItiATRules & 3 & 278828016 & 005 & 92942 & 2672002 & 203.93 & $<.0001$ \\
\hline GTRules*ATRules & 6 & 2502124 & 108 & 41702 & 0684.67 & 0.91 & 0.5416 \\
\hline
\end{tabular}

Fig. 7 ANOVA table for fuel burn as a dependent variable.

Table 2a shows the interaction plot for itinerary and air traffic rules using the response variable as sequence actions, and the same type of plots using the response variable the number of conflicts. The plots of sequence actions show that the air traffic rule level 1 , which is $3 \mathrm{NM}$ miles, minimizes the numbers of sequence actions. In contrast, the plots of numbers of conflicts present that the air traffic rule level 3, which is $7 \mathrm{NM}$ miles, minimizes the numbers of conflicts and the level 1 of "ATRules" is the worst for this purpose.

In addition, Table $2 \mathrm{~b}$ shows the interaction plot for itinerary and air traffic rules using the response variable the flight time and the same kind of plot using the response variable - the track mile distance. The plots of flight time and track mile distance show the same. The air traffic rule at level 1 minimizes both response variables.

Finally, Table 2c shows the interaction plot for itinerary and air traffic rules using the response variable - the Fuel Burn. This plots shows that the level 1 of Air traffic rules minimizes the fuel burn. Therefore, there is an issue between the interaction plot results from the number of conflict and the others interaction plots, since the level 1 of air traffic rules minimizes all the response variables except the number of conflict, which is maximized.

\subsection{Pairwise Tukey Comparison}

In order to conduct the corresponding family of tests of the form:

$$
\begin{aligned}
& \mathrm{H}_{\mathrm{o}}: \mathrm{D}=0 . \\
& \mathrm{H}_{1}: \mathrm{D} \neq 0 .
\end{aligned}
$$

The objective is to find the significance of the comparison. So, if 0 is included in the confidence interval, it means that it is not statistically significant.

\subsubsection{Sequence Actions}

Fig. 8 shows the 36 pairwise comparison of Tukey. Consequently, Fig. 8 shows the following information.

All the comparisons are statistically significant, except: 
Table 2a Interaction plot summary.

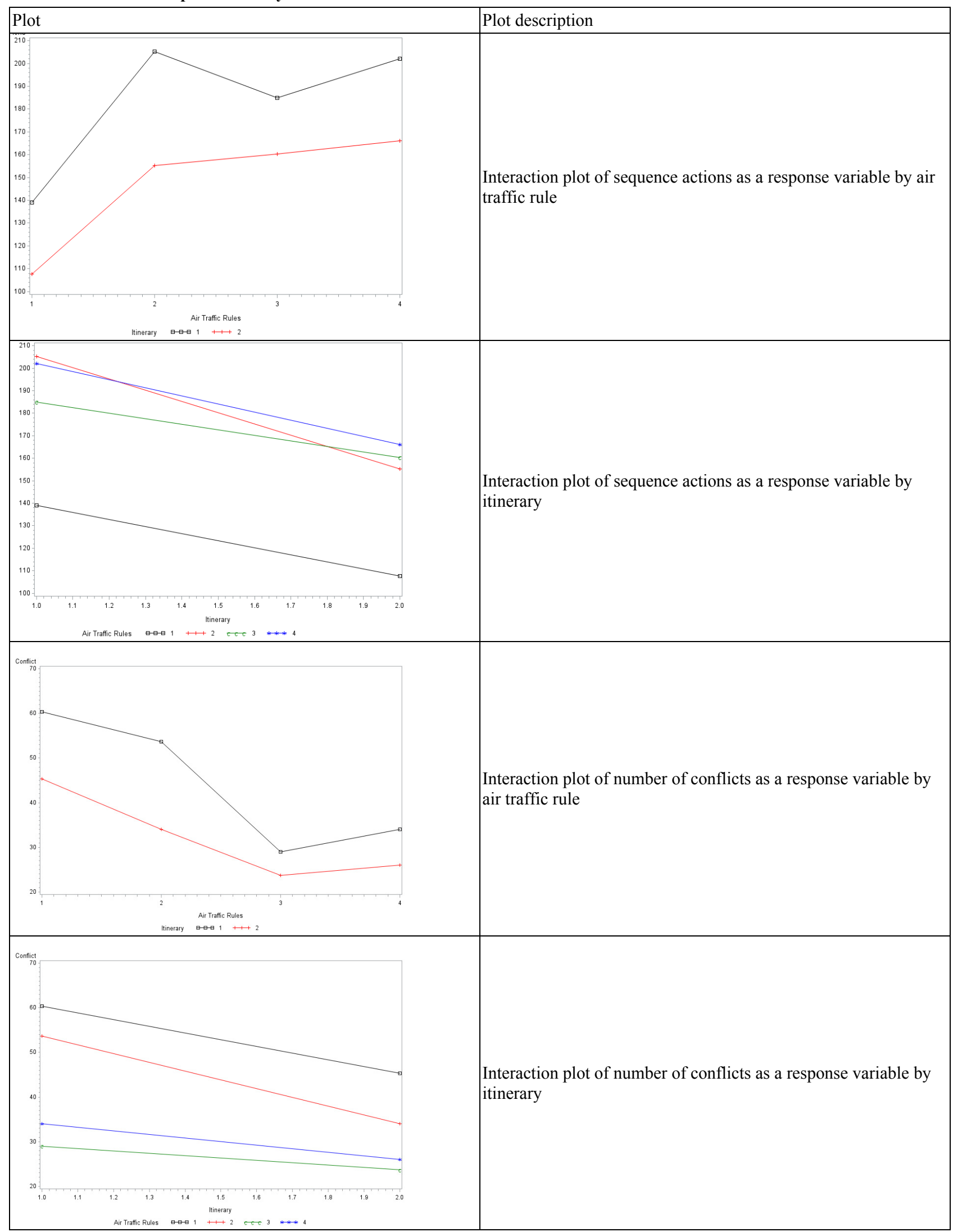


Table 2b Interaction plot summary.

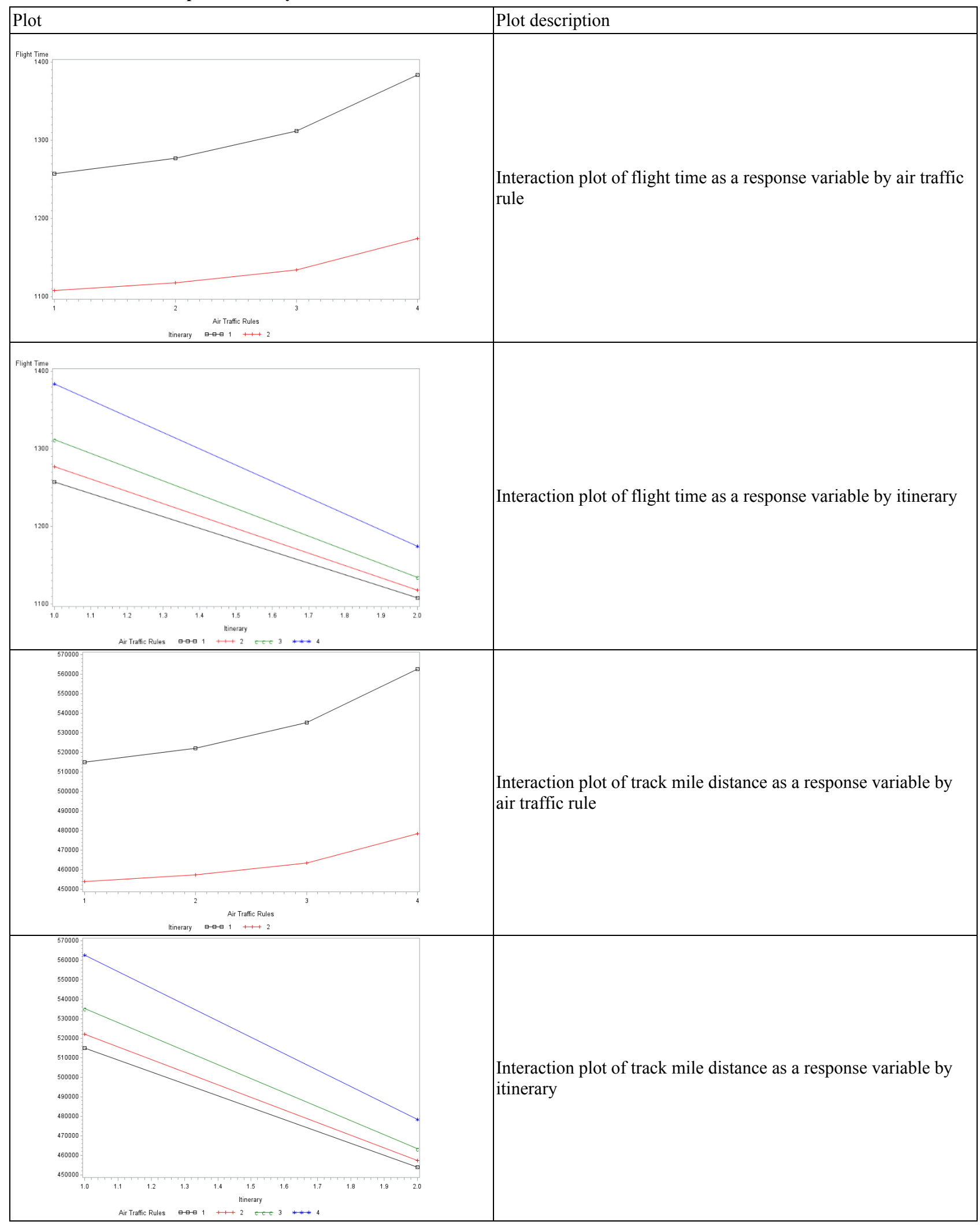


Table 2c Interaction plot summary.

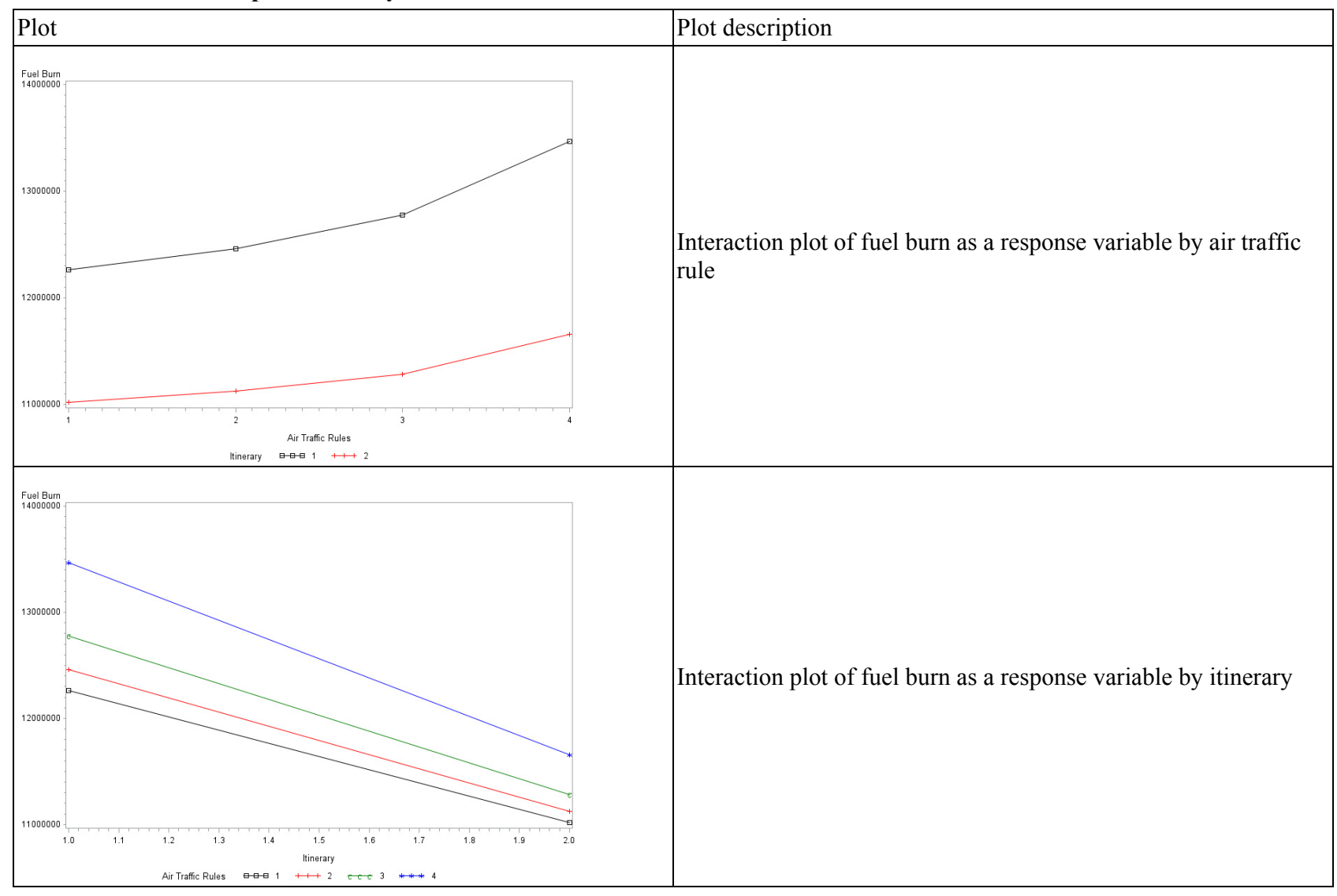

(1) The comparison between sequencing actions when the interaction is high season itinerary and 5 $\mathrm{NM}$ as air traffic rule and the sequencing actions when the interaction is high season itinerary and $10 \mathrm{NM}$.

(2) The comparison between sequencing actions when the interaction is low season itinerary and $5 \mathrm{NM}$ as air traffic rule and the sequencing actions when the interaction is low season itinerary and $7 \mathrm{NM}$.

(3) The comparison between sequencing actions when the interaction is low season itinerary and $7 \mathrm{NM}$ and the sequencing actions when the interaction is low season itinerary and $10 \mathrm{NM}$ as air traffic rule.

\subsubsection{Number of Conflicts}

Fig. 9 shows that the majority of the comparisons are significant because they are not including 0 in the Tukey confidence interval. The following are the exceptions:

(1) High Season Itinerary with $3 \mathrm{NM}$ vs. High Season Itinerary with $5 \mathrm{NM}$.
(2) High Season Itinerary with $5 \mathrm{NM}$ vs. Low Season Itinerary with 3 NM.

(3) High Season Itinerary with $7 \mathrm{NM}$ vs. High Season Itinerary with 10 NM.

(4) High Season Itinerary with $7 \mathrm{NM}$ vs. Low Season Itinerary with 5 NM.

(5) High Season Itinerary with $7 \mathrm{NM}$ vs. Low Season Itinerary with $7 \mathrm{NM}$.

(6) High Season Itinerary with $7 \mathrm{NM}$ vs. Low Season Itinerary with $10 \mathrm{NM}$.

(7) High Season Itinerary with $10 \mathrm{NM}$ vs. Low Season Itinerary with $5 \mathrm{NM}$.

(8) High Season Itinerary with $10 \mathrm{NM}$ vs. Low Season Itinerary with $10 \mathrm{NM}$.

(9) Low Season Itinerary with $5 \mathrm{NM}$ vs. Low Season Itinerary with 10NM.

(10) Low Season Itinerary with $5 \mathrm{NM}$ vs. Low Season Itinerary with 10 NM.

(8) High Season Itinerary with $10 \mathrm{NM}$ vs. Low 


\begin{tabular}{|c|c|c|c|c|}
\hline \multicolumn{5}{|c|}{ Least Squares Means for Effect Iti*ATRules } \\
\hline $\mathbf{i}$ & $\mathbf{j}$ & $\begin{array}{r}\text { Difference Between } \\
\text { Means }\end{array}$ & $\begin{array}{r}\text { Simultaneous } 90 \% \\
\text { for LSMean }\end{array}$ & $\begin{array}{l}\text { ence Limits } \\
\text { ean(j) }\end{array}$ \\
\hline 1 & 2 & -68.333333 & -74.101787 & -58.564879 \\
\hline 1 & 3 & -48.000000 & -53.788454 & -38.231546 \\
\hline 1 & 4 & -63.000000 & -70.788454 & -55.231546 \\
\hline 1 & 5 & 31.333333 & 23.584879 & 39.101787 \\
\hline 1 & 6 & -16.333333 & -24.101787 & -8.564879 \\
\hline 1 & 7 & -21.333333 & -29.101787 & -13.584879 \\
\hline 1 & 8 & -27.000000 & -34.788454 & -19.231546 \\
\hline 2 & 3 & 20.333333 & 12.584879 & 28.101787 \\
\hline 2 & 4 & 3.333333 & -4.435121 & 11.101787 \\
\hline 2 & 5 & 97.686887 & 89.898213 & 105.435121 \\
\hline 2 & 6 & 50.000000 & 42.231548 & 57.768454 \\
\hline 2 & 7 & 45.000000 & 37.231548 & 52.768454 \\
\hline 2 & 8 & 39.333333 & 31.584879 & 47.101787 \\
\hline 3 & 4 & -17.000000 & -24.768454 & -9.231546 \\
\hline
\end{tabular}

\begin{tabular}{|c|c|c|c|c|}
\hline \multicolumn{5}{|c|}{ Least Squares Means for Effect Iti*ATRules } \\
\hline i & $\mathbf{j}$ & $\begin{array}{r}\text { Difference Between } \\
\text { Means }\end{array}$ & $\begin{array}{r}\text { Simultaneous } 909 \\
\text { for LSMean }\end{array}$ & $\begin{array}{l}\text { lence Limits } \\
\text { lean(j) }\end{array}$ \\
\hline 3 & 5 & 77.333333 & 69.584879 & 85.101787 \\
\hline 3 & 6 & 29.686887 & 21.898213 & 37.435121 \\
\hline 3 & 7 & 24.668687 & 16.898213 & 32.435121 \\
\hline 3 & 8 & 19.000000 & 11.231548 & 26.768454 \\
\hline 4 & 5 & 94.333333 & 88.584879 & 102.101787 \\
\hline 4 & 6 & 46.686887 & 38.898213 & 54.435121 \\
\hline 4 & 7 & 41.686887 & 33.898213 & 49.435121 \\
\hline 4 & 8 & 38.000000 & 28.231548 & 43.768454 \\
\hline 5 & 6 & -47.668687 & -55.435121 & -39.898213 \\
\hline 5 & 7 & -52.668687 & -60.435121 & -44.898213 \\
\hline 5 & 8 & -58.333333 & -68.101787 & -50.564879 \\
\hline 6 & 7 & -5.000000 & -12.788454 & 2.768454 \\
\hline 6 & 8 & -10.686867 & -18.435121 & -2898213 \\
\hline 7 & 8 & -5.686887 & -13.435121 & 2.101787 \\
\hline
\end{tabular}

Fig. 8 Pairwise Tukey comparison for sequence actions.

\begin{tabular}{|c|c|c|c|c|}
\hline \multicolumn{5}{|c|}{ Least Squares Means for Effect Iti*ATRules } \\
\hline & \multirow{2}{*}{$\begin{array}{l}\text { j } \\
2\end{array}$} & \multirow{2}{*}{$\begin{array}{r}\text { Difference Between } \\
\text { Means } \\
6.668687\end{array}$} & \multicolumn{2}{|c|}{$\begin{array}{l}\text { Simultaneous } 90 \% \text { Confidence Limits } \\
\text { for LSMean(i)-LSMean(i) }\end{array}$} \\
\hline & & & -2.004479 & 15.337812 \\
\hline 1 & 3 & 31.333333 & 22.682188 & 40.004479 \\
\hline 1 & 4 & 26.333333 & 17.682188 & 35.004479 \\
\hline 1 & 5 & 15.000000 & 6.328854 & 23.671146 \\
\hline 1 & 6 & 26.333333 & 17.682188 & 35.004479 \\
\hline 1 & 7 & 38.686887 & 27.995521 & 45.337812 \\
\hline 1 & 8 & 34.333333 & 25.682188 & 43.004479 \\
\hline 2 & 3 & 24.686887 & 15.995521 & 33.337812 \\
\hline 2 & 4 & 19.686887 & 10.995521 & 28.337812 \\
\hline 2 & 5 & 8.333333 & -0.337812 & 17.004479 \\
\hline 2 & 6 & 19.668687 & 10.995521 & 28.337812 \\
\hline 2 & 7 & 30.000000 & 21.328854 & 38.671146 \\
\hline 2 & 8 & 27.686887 & 18.995521 & 36.337812 \\
\hline 3 & 4 & -5.000000 & -13.671146 & 3.671146 \\
\hline
\end{tabular}

\begin{tabular}{|c|c|c|c|c|}
\hline \multicolumn{5}{|c|}{ Least Squares Means for Effect ItiATRules } \\
\hline \multirow{2}{*}{$\begin{array}{l}\mathrm{i} \\
3\end{array}$} & \multirow{2}{*}{$\begin{array}{l}\mathrm{j} \\
5\end{array}$} & \multirow{2}{*}{$\begin{array}{r}\text { Difference Between } \\
\text { Means } \\
-16.333333\end{array}$} & \multicolumn{2}{|c|}{$\begin{array}{l}\text { Simultaneous } 90 \% \text { Confidence Limits } \\
\text { for LSMean(i)-LSMean(j) }\end{array}$} \\
\hline & & & -25.004479 & -7.682188 \\
\hline 3 & 6 & -5.000000 & -13.671146 & 3.671146 \\
\hline 3 & 7 & 5.333333 & -3.337812 & 14.004479 \\
\hline 3 & 8 & 3.000000 & -5.671148 & 11.671148 \\
\hline 4 & 5 & -11.333333 & -20.004479 & -2.682188 \\
\hline 4 & 6 & 0 & -8.671148 & 8.671148 \\
\hline 4 & 7 & 10.333333 & 1.682188 & 19.004479 \\
\hline 4 & 8 & 8.000000 & -0.671148 & 16.671148 \\
\hline 5 & 6 & 11.333333 & 2.682188 & 20.004479 \\
\hline 5 & 7 & 21.686887 & 12995521 & 30.337812 \\
\hline 5 & 8 & 19.333333 & 10.682188 & 28.004479 \\
\hline 6 & 7 & 10.333333 & 1.682188 & 19.004479 \\
\hline 6 & 8 & 8.000000 & -0.671148 & 16.671146 \\
\hline 7 & 8 & -2.333333 & -11.004479 & 6.337812 \\
\hline
\end{tabular}

Fig. 9 Pairwise Tukey comparison for number of conflicts. 

Air Traffic Flow Optimization in Panama

\begin{tabular}{|c|c|c|c|c|}
\hline \multicolumn{5}{|c|}{ Least Squares Means for Effect ItiATRules } \\
\hline $\mathbf{i}$ & $\mathbf{j}$ & $\begin{array}{r}\text { Difference Between } \\
\text { Means }\end{array}$ & $\begin{array}{r}\text { Simultaneous } 90 \% \\
\text { for LSMean }\end{array}$ & $\begin{array}{l}\text { dence Limits } \\
\text { Mean(j) }\end{array}$ \\
\hline 1 & 2 & -19.803333 & -25.329599 & -14.277088 \\
\hline 1 & 3 & -54.110000 & -59.638268 & -48.583734 \\
\hline 1 & 4 & -125.900000 & -131.426268 & -120.373734 \\
\hline 1 & 5 & 149.456887 & 143.930401 & 154.982932 \\
\hline 1 & 6 & 139.676887 & 134. 150401 & 145.202932 \\
\hline 1 & 7 & 123.150000 & 117.623734 & 128.678268 \\
\hline 1 & 8 & 83.378687 & 77.850401 & 88.902932 \\
\hline 2 & 3 & -34.306887 & -39.832982 & -28.780401 \\
\hline 2 & 4 & -108.096887 & -111.622932 & -100.570401 \\
\hline 2 & 5 & 169.260000 & 163.733734 & 174.786268 \\
\hline 2 & 6 & 159.480000 & 153.963734 & 185.006268 \\
\hline 2 & 7 & 142.953333 & 137.427088 & 148.479699 \\
\hline 2 & 8 & 103.180000 & 97.653734 & 108.708268 \\
\hline 3 & 4 & -71.790000 & -77.316268 & -68.263734 \\
\hline
\end{tabular}

\begin{tabular}{|c|c|c|c|c|}
\hline \multicolumn{5}{|c|}{ Least Squares Means for Effect Iti*ATRules } \\
\hline i & j & $\begin{array}{r}\text { Difference Between } \\
\text { Means }\end{array}$ & $\begin{array}{r}\text { Simultaneous } 90 \% \\
\text { for LSMean }\end{array}$ & $\begin{array}{l}\text { lence Limits } \\
\text { ean(j) }\end{array}$ \\
\hline 3 & 5 & 203.568687 & 198.040401 & 209.092932 \\
\hline 3 & 6 & 193.786887 & 188.260401 & 199.312932 \\
\hline 3 & 7 & 177.260000 & 171.733734 & 182.786288 \\
\hline 3 & 8 & 137.488687 & 131.960401 & 143.012932 \\
\hline 4 & 5 & 275.358687 & 269.830401 & 280.882932 \\
\hline 4 & 6 & 265.576867 & 260.050401 & 271.102932 \\
\hline 4 & 7 & 249.050000 & 243.523734 & 254.578268 \\
\hline 4 & 8 & 209.276887 & 203.750401 & 214.802932 \\
\hline 5 & 6 & -9.780000 & -15.308268 & -4.253734 \\
\hline 5 & 7 & -26.308687 & -31.832932 & -20.780401 \\
\hline 5 & 8 & -68.080000 & -71.608268 & -60.553734 \\
\hline 6 & 7 & -16.526867 & -22052982 & -11.000401 \\
\hline 6 & 8 & -58.300000 & -61.826268 & -50.773734 \\
\hline 7 & 8 & -39.773333 & -45.299699 & -34.247088 \\
\hline
\end{tabular}

Fig. 10a Pairwise Tukey comparison for flight time.

\begin{tabular}{|c|c|c|c|c|}
\hline \multicolumn{5}{|c|}{ Least Squares Means for Effect ItiATRules } \\
\hline i & j & $\begin{array}{r}\text { Difference Between } \\
\text { Means }\end{array}$ & $\begin{array}{r}\text { Simultaneous } 90 \% \\
\text { for LSMean }\end{array}$ & $\begin{array}{l}\text { iidence Limits } \\
\text { Mean(j) }\end{array}$ \\
\hline 1 & 2 & -7177.333333 & -9651.327122 & -4803.339645 \\
\hline 1 & 3 & -20115 & -22489 & -17741 \\
\hline 1 & 4 & -47727 & -50101 & -45353 \\
\hline 1 & 5 & 61289 & 58915 & 63683 \\
\hline 1 & 6 & 57832 & 55258 & 60006 \\
\hline 1 & 7 & 51735 & 49381 & 54109 \\
\hline 1 & 8 & 36755 & 34381 & 39129 \\
\hline 2 & 3 & -12908 & -15312 & -10584 \\
\hline 2 & 4 & -40550 & -42924 & -38176 \\
\hline 2 & 5 & 68487 & 68093 & 70841 \\
\hline 2 & 6 & 64809 & 62435 & 67183 \\
\hline 2 & 7 & 58912 & 58538 & 61286 \\
\hline 2 & 8 & 43932 & 41558 & 48306 \\
\hline 3 & 4 & -27812 & -29986 & -25238 \\
\hline
\end{tabular}

\begin{tabular}{|c|c|c|c|c|}
\hline \multicolumn{5}{|c|}{ Least Squares Means for Effect Iti*ATRules } \\
\hline i & j & $\begin{array}{r}\text { Difference Between } \\
\text { Means }\end{array}$ & $\begin{array}{l}\text { Simultaneous } 90 \% \\
\text { for LSMeant }\end{array}$ & $\begin{array}{l}\text { fidence Limits } \\
\text { Mean(j) }\end{array}$ \\
\hline 3 & 5 & 81404 & 79030 & 83778 \\
\hline 3 & 6 & 77747 & 75373 & 80121 \\
\hline 3 & 7 & 71850 & 69478 & 74224 \\
\hline 3 & 8 & 58870 & 54496 & 59244 \\
\hline 4 & 5 & 109017 & 108843 & 111391 \\
\hline 4 & 6 & 105359 & 102985 & 107733 \\
\hline 4 & 7 & 99482 & 97088 & 101836 \\
\hline 4 & 8 & 84482 & 82108 & 88856 \\
\hline 5 & 6 & -3657.333333 & -6031.327122 & -1283.339545 \\
\hline 5 & 7 & -9554.686887 & -11929 & -7180.672878 \\
\hline 5 & 8 & -24535 & -26909 & -22181 \\
\hline 6 & 7 & -5897.333333 & -8271.327122 & -3523.339545 \\
\hline 6 & 8 & -20877 & -23251 & -18503 \\
\hline 7 & 8 & -14980 & -17354 & -12606 \\
\hline
\end{tabular}

Fig. 10b Pairwise Tukey comparison for track mile distance. 


\begin{tabular}{|c|c|c|c|c|}
\hline \multicolumn{5}{|c|}{ Least Squares Means for Effect Iti*ATRules } \\
\hline i & j & $\begin{array}{r}\text { Difference Between } \\
\text { Means }\end{array}$ & $\begin{array}{l}\text { Simultaneous } 90 \% \\
\text { for LSMean }\end{array}$ & $\begin{array}{l}\text { ce Limits } \\
\text { n(j) }\end{array}$ \\
\hline 1 & 2 & -199774 & -263477 & -138071 \\
\hline 1 & 3 & -516002 & -579705 & -452299 \\
\hline 1 & 4 & -1209758 & -1273482 & -1146055 \\
\hline 1 & 5 & 1248276 & 1182573 & 1309979 \\
\hline 1 & 6 & 1138233 & 1074530 & 1201938 \\
\hline 1 & 7 & 979001 & 915298 & 1042704 \\
\hline 1 & 8 & 603498 & 539795 & 687201 \\
\hline 2 & 3 & -316228 & -379982 & -252525 \\
\hline 2 & 4 & -1009984 & -1073688 & -948281 \\
\hline 2 & 5 & 1448050 & 1382347 & 1509753 \\
\hline 2 & 6 & 1338007 & 1274304 & 1401710 \\
\hline 2 & 7 & 1178775 & 1115071 & 1242478 \\
\hline 2 & 8 & 803272 & 739589 & 868975 \\
\hline 3 & 4 & -693756 & -757469 & -630053 \\
\hline
\end{tabular}

Fig. 10c Pairwise Tukey comparison for fuel burn.

Season Itinerary with 10 NM.

(9) Low Season Itinerary with $5 \mathrm{NM}$ vs. Low Season Itinerary with 10NM.

(10) Low Season Itinerary with $5 \mathrm{NM}$ vs. Low Season Itinerary with $10 \mathrm{NM}$.

4.3.3 Flight Time, Track Mile Distance and Fuel Burn

Figs. 10a-10c show that none of the comparison include 0 in the interval, so all of them are statistically significant.

\section{Conclusions and Further Research}

As a conclusion, the three factors' complete factorial design linear model is statistically significant at 0.1 level of significance. However, the ground traffic rules are not significant at 0.1 level of significance, so it has not effect in the air traffic KPIs.

The main objective of the simulation model is to minimize the air traffic KPIs, so the interaction plots show that the level 1 of air traffic rules is the best to minimize the number of sequence actions, the flight time, the track mile distance and the fuel burn, but not number of conflicts. The number of conflicts is

\begin{tabular}{|c|c|c|c|c|}
\hline \multicolumn{5}{|c|}{ Least Squares Means for Effect ItiATRules } \\
\hline \multirow{2}{*}{$\begin{array}{l}\mathrm{i} \\
3\end{array}$} & \multirow{2}{*}{$\begin{array}{l}\mathrm{j} \\
5\end{array}$} & \multirow{2}{*}{$\begin{array}{r}\text { Difference Between } \\
\text { Means } \\
1762278\end{array}$} & \multicolumn{2}{|c|}{$\begin{array}{l}\text { Simultaneous } 90 \% \text { Confidence Limits } \\
\text { for LSMean(i)-LSMean(i) }\end{array}$} \\
\hline & & & 1698575 & 1826982 \\
\hline 3 & 6 & 1654235 & 1590532 & 1717938 \\
\hline 3 & 7 & 1495003 & 1431300 & 1558706 \\
\hline 3 & 8 & 1119600 & 1055797 & 1183203 \\
\hline 4 & 5 & 2456034 & 2392331 & 2519738 \\
\hline 4 & 6 & 2347991 & 2284288 & 2411695 \\
\hline 4 & 7 & 2188759 & 2125058 & 2252462 \\
\hline 4 & 8 & 1813258 & 1749553 & 1878960 \\
\hline 5 & 6 & -108043 & -171748 & -44340 \\
\hline 5 & 7 & -287275 & -330979 & -203572 \\
\hline 5 & 8 & -642778 & -708481 & -579075 \\
\hline 6 & 7 & -159232 & -222905 & -96529 \\
\hline 6 & 8 & -534735 & -598438 & -471032 \\
\hline 7 & 8 & -375503 & -439208 & -311799 \\
\hline
\end{tabular}

reduced by the level 3 and the level 1 has the worst impact on it.

Based on the Tukey pairwise comparison, the analysis when the number of conflicts is the response variable appears to have 10 over 36 comparisons as not statistically significant, which include four of the eight comparisons using the level 3 of air traffic rules. The level 3 of air traffic rules is the one which minimizes the number of conflicts based on the interaction plots.

As a further research, another experiment can include more factors in the model, such as, the wind, the weather events, the aircraft weight, domestic flights, over flights, aircraft speed and altitude. Then, there is the opportunity to run set of experiments to understand how the correlation between response variables is. In addition, there is the opportunity to conduct stochastic experiments instead of deterministic outputs. In addition, a future experimentation can run different simulation models, including the tested before, using all the factors that has an effect over the air traffic KPIs. Finally, we can conduct a multi-objective stochastic model to evaluate financial risk based on cost and safety [20]. 


\section{Acknowledgments}

This research was sponsored by the RAID Lab from the University of Texas at Arlington. The author would like to thank Autoridad de Aereonautica Civil, COPA Airlines, and Tocumen, S. A.

\section{References}

[1] Global Market Forecast 2016-2035. 2016. "Mapping Demand." Accessed May 10, 2016. http://www.airbus.com/company/market/global-market-f orecast-2016-2035/.

[2] ALG Consulting. 2015. Power Point Reports. ALG report.

[3] Gelhausen, M., Berster, P., and Wilken, D. 2013. "Do Airport Capacity Constraints Have a Serious Impact on the Future Development of Air Traffic?" Journal of Air Transport Management 28: 3-13.

[4] Bevilacqua, M., Ciarapica, F. E., Mazzuto, G., and Postacchini, L. 2012. "Air Traffic Management of an Airport using Discrete Event Simulation Method." In Proceedings of 2012 IEE International Conference on Industrial Engineering and Engineering Management, 1034-8.

[5] Cedeño, M., Suira, A., and Guerra de Castillo, Z. 2013. "Simulation Model Applied in Passenger's Flow at Latin American Airport Hub." Paper presented on Eleventh Latin American and Caribbean Conference for Engineering and Technology, Cancun, Mexico.

[6] NextGen Works. 2016. "Federal Aviation Administration.” Accessed May 2, 2015. http://www.faa.gov/nextgen/.

[7] Point Merge. 2016. "Improving and Harmonising Arrival Operations with Existing Technology." EUROCONTROL. Accessed May 12, 2016. https://www. eurocontrol.int/services/point-merge-concept/.

[8] Ivanescu, D., Shaw, Ch., Zeghal, K., and Hoffman, E. 2007. "Propagation of Airborne Sapcing Errors in Merging Traffic Streams." Paper presented on 7th USA/Europe Air Traffic Management R\&D Seminar, Barcelona, Spain.
[9] Ivanescu, D., Shaw, Ch., and Tamvaclis, C. 2009. "Models of Air Traffic Merging Techniques: Evaluating Performance of Point Merge." Paper presented on 9th AIAA Aviation Technology, Integration and Operations Conference (ATIO), South Carolina, USA.

[10] Ozlem, M. 2015. "Optimum Arrival Routes for Flight Efficiency." Journal of Power and Energy Engineering 3: 449-52.

[11] Current Market Outlook 2015-2034. 2015. "Boeing." Accessed June 1, 2016. www.boeing.com/resources/ boeingdotcom/commercial/about-our-market/assets/down loads/Boeing_Current_Market_Outlook_2015.pdf.

[12] World Air Cargo Forecast 2014-2015. 2014. "Boeing World Air Cargo Forecast Team 2014.” Accessed May 1, 2015. www.boeing.com/commercial/cargo.

[13] Oglivie, C. 2015. "Airspace Re-design Project/PBN Concept-MPTO.” Copa Airlines.

[14] Tocumen International Airport. Technical Aspects. 2016. Accessed June 2, 2016. http://www.tocumenpanama. aero/datos-tecnicos/.

[15] Lee, H., and Balakrishnan, H. 2012. "Fast-Time Simulations of Detroit Airport Operations for Evaluating Performance in the Presence of Uncertainties." Paper presented on Massachusetts Institute of Techonology, Cambridge, MA.

[16] Simaiakis, I., and Balakrishnan, H. 2014. "Design and Simulation of Airport Congestion Control Algorithms." Paper presented on 2014 American Control Conference, Portland Oregon, USA.

[17] Chen, V., Tsui, K., Barton, R., and Meckesheimer, M. 2006. "A Review of Design and Modeling in Computer Experiments." IIE Transactions 38 (4): 273-91.

[18] Total Airspace and Airport Modeller (TAAM). 2015. Product Profile 2015. Jepessesen a Boeing Company.

[19] Hub of the Americas. 2016. "Copa Airlines." Accessed June 15, 2016. https://www.copaair.com/en/web/us/ hub-of-the-americas/.

[20] Jones, E., Franca, R., Richards, C., and Carlson, J. 2010. "Multi-objective Stochastic Supply Chain Modeling to Evaluate Tradeoffs between Profit and Quality." International Journal of Production Economics 127 (2): 292-9. 
Appendix

Table A Final output table with factors non-coded.

\begin{tabular}{|c|c|c|c|c|c|c|c|}
\hline $\begin{array}{c}\text { Factor 1 } \\
\text { (Season } \\
\text { Itinerary) }\end{array}$ & $\begin{array}{c}\text { Factor 2 } \\
\text { (GTR in } \\
\text { min) }\end{array}$ & $\begin{array}{c}\text { Factor 3 } \\
\text { (ATR in } \\
\text { NM) }\end{array}$ & $\begin{array}{c}\text { Sequencing } \\
\text { Actions }\end{array}$ & $\begin{array}{c}\text { Airborne } \\
\text { Conflicts }\end{array}$ & $\begin{array}{c}\text { Flight Time } \\
\text { (hr) }\end{array}$ & $\begin{array}{c}\text { Track mile } \\
\text { Distance } \\
\text { (NM) }\end{array}$ & $\begin{array}{c}\text { Fuel Burn } \\
\text { (gal) }\end{array}$ \\
\hline High & 1 & 3 & 137 & 64 & 1258.46 & 515487 & 12271268 \\
\hline High & 1 & 5 & 206 & 54 & 1277.84 & 522541 & 12466300 \\
\hline High & 1 & 7 & 184 & 29 & 1312.49 & 535583 & 12786031 \\
\hline High & 1 & 10 & 202 & 35 & 1380.63 & 561639 & 13442690 \\
\hline High & 1.5 & 3 & 141 & 59 & 1258.03 & 515304 & 12266665 \\
\hline High & 1.5 & 5 & 207 & 53 & 1278.39 & 522692 & 12472031 \\
\hline High & 1.5 & 7 & 186 & 30 & 1312.39 & 535516 & 12784460 \\
\hline High & 1.5 & 10 & 202 & 34 & 1381.53 & 562026 & 13447395 \\
\hline High & 2 & 3 & 139 & 58 & 1255.94 & 514381 & 12245092 \\
\hline High & 2 & 5 & 203 & 54 & 1275.61 & 521471 & 12444015 \\
\hline High & 2 & 7 & 185 & 28 & 1309.88 & 534418 & 12760540 \\
\hline High & 2 & 10 & 202 & 33 & 1387.97 & 564689 & 13522214 \\
\hline Low & 1 & 3 & 106 & 45 & 1108.78 & 454097 & 11021999 \\
\hline Low & 1 & 5 & 162 & 38 & 1118.58 & 457705 & 11129769 \\
\hline Low & 1 & 7 & 161 & 26 & 1134.79 & 463540 & 11287277 \\
\hline Low & 1 & 10 & 166 & 27 & 1174.85 & 478648 & 11667771 \\
\hline Low & 1.5 & 3 & 106 & 41 & 1108.29 & 453880 & 11016673 \\
\hline Low & 1.5 & 5 & 148 & 33 & 1117.78 & 457430 & 11123641 \\
\hline Low & 1.5 & 7 & 160 & 24 & 1134.42 & 463362 & 11283283 \\
\hline Low & 1.5 & 10 & 166 & 26 & 1173.84 & 478202 & 11656437 \\
\hline Low & 2 & 3 & 111 & 50 & 1106.99 & 453327 & 11005525 \\
\hline Low & 2 & 5 & 156 & 31 & 1117.04 & 457141 & 11114915 \\
\hline Low & 2 & 7 & 160 & 21 & 1133.77 & 463066 & 11275462 \\
\hline Low & 2 & 10 & 166 & 25 & 1173.61 & 478058 & 11648322 \\
\hline
\end{tabular}

Table A shows the non-coded factors with their levels. The output obtained per each response variable is in the table as well. 